EDITORIAL

\title{
Hibernating myocardium: high or low risk?
}

\section{J H McGowan}

Heart 2004;90:237-238. doi: 10.1136/heart.2003.021006

The optimal strategy for risk stratification in heart failure continues to evolve, with increasing numbers of tools such as natriuretic peptide assessment being utilised

$\mathrm{T}$ he assessment of risk, and its subsequent manipulation, accounts for a large amount of what we do in cardiology. Among the heart failure population, increasing numbers of tools are being utilised for the purpose. In this issue of Heart, Schinkel and colleagues ${ }^{1}$ present data on the combined use of both physiological and biochemical markers of risk in heart failure.

Many studies have shown that, as a screening test, a low concentration of natriuretic peptide in patients with suspected heart failure has a high negative predictive value. ${ }^{2}$ Furthermore, in patients with the diagnosis, variation in natriuretic peptide concentration may predict subsequent hospitalisation and death. ${ }^{3}{ }^{4}$

The study by Schinkel and colleagues ${ }^{1}$ found that natriuretic peptide values were substantially lower in patients without heart failure, which is entirely consistent with previous findings. The investigators then examined contractile reserve in those patients with ischaemic left ventricular (LV) dysfunction, using low dose dobutamine stress echocardiography (DSE). They concluded that the presence of contractile reserve was associated with a lower concentration of natriuretic peptide. They go on to suggest that the absence of contractile reserve in patients with elevated natriuretic peptides predicts a higher risk of future events.

\section{HIBERNATION VERSUS STUNNING}

In their article, Schinkel and colleagues ${ }^{1}$ avoid the use of the terms "hibernation" and "stunning", perhaps because of controversy over what these entities actually represent. This is unfortunate because the differences between these two pathophysiologies, or more importantly how they typically present, are key to interpreting the literature. "Stunning" can be defined as postischaemic myocardial dysfunction, and has been well documented in a number of clinical scenarios. Perhaps the most common, and which the authors refer to, is following reperfusion in acute myocardial infarction (MI). Here the myocardium may remain stunned for several days in the face of a normal blood supply. The demonstration of contractile reserve by DSE in this situation has been shown to predict recovery of function, ${ }^{5}$ which is associated with improved long term prognosis. However, this is a quite different scenario to the patient with chronic heart failure, as in the present study.
Correspondence to:
Dr James H McGowa Cardiothoracic Unit, James Cook University Hospital, Middlesbrough TS5 3BW, ....................
The term "hibernation" describes chronically dysfunctional myocardium with the potential to recover following revascularisation. The pathophysiology of hibernation is less well understood than stunning, although it may well represent a process of repetitive stunning. However, the important difference between the two scenarios is that in hibernation, a chronically stenosed vessel subtends the myocardium in question. Coronary flow reserve is reduced, although flow at rest may be near normal. ${ }^{6}$ Using DSE, contractile reserve, and in particular a biphasic response, is likely to be seen..$^{7-9}$ However, unlike stunning in the post-MI patient, there is evidence that the presence of hibernation in these patients predicts a worse outcome. ${ }^{1011}$ Furthermore, revascularisation may improve prognosis substantially. ${ }^{10}$ A randomised controlled trial of this strategy is presently underway. ${ }^{12}$

\section{THE IMPORTANCE OF CONTROL}

The suggestion by Schinkel and colleagues ${ }^{1}$ of the value of a combined assessment of natriuretic peptides and contractile reserve-that is, hibernation-in patients with ischaemic LV dysfunction is a good one. However, their finding that hibernation was associated with a lower natriuretic peptide concentration is questionable. An important limitation of their data analysis is that they did not control for LV systolic function at rest. To suggest that all patients with an echocardiographic ejection fraction (EF) $\leqslant 40 \%$ had severe LV systolic dysfunction is misleading. ${ }^{13}$ Natriuretic peptide secretion is influenced by the degree of LV stretch, with EF one, albeit crude, indicator of this. ${ }^{14}$ Variations in EF within the range $\leqslant 40 \%$ could have exerted an important influence on the results. Without controlling for resting EF in the analysis, a reliable interpretation of the data cannot be made.

In defining contractile reserve, the authors decided to use a threshold of improvement in $\geqslant 2$ severely hypokinetic segments in the 16 segment LV model. In clinical practice, improvement in $\geqslant 4 / 16$ segments has been utilised as a threshold for benefit with revascularisation, although there is little evidence to support this. In the study, however, it would also have been feasible, and arguably better, to treat contractile reserve as a continuous variable. It could then have been used in a multivariate model along with natriuretic peptide and EF to test for association. Furthermore, the scatter plot of the

Abbreviations: LV, left ventricular; DSE, dobutamine stress echocardiography; $\mathrm{MI}$, myocardial infarction; EF, ejection fraction 
data clearly shows that variables are not distributed normally, and non-parametric testing would therefore seem more appropriate. In doing so, it is less likely that differences would have been significant.

For all these reasons, some of the conclusions of the study should be regarded with caution. Nevertheless the optimal strategy for risk stratification in heart failure continues to evolve. In time, natriuretic peptide may be measured routinely as a means of assessing disease severity. In those with ischaemic heart disease, at highest risk, evidence of hibernation should lead towards revascularisation.

\section{REFERENCES}

1 Schinkel AFL, Vourvouri EC, Bax JJ, et al. Relation between left ventricular contractile reserve during low dose dobutamine echocardiography and plasma concentrations of natriuretic peptides. Heart 2004;90:293-6.

2 de Lemos JA, McGuire DK, Drazner MH. B-type natriuretic peptide in cardiovascular disease. Lancet 2003;362:316-22.

3 Harrison A, Morrison LK, Krishnaswamy P, et al. B-type natriuretic peptide predicts future cardiac events in patients presenting to the emergency department with dyspnea. Ann Emerg Med 2002;39:131-8.

4 Berger R, Huelsman M, Strecker K, et al. B-type natriuretic peptide predicts sudden death in patients with chronic heart failure. Circulation 2002:105:2392-7.

5 Smart SC, Sawada S, Ryan T, et al. Low-dose dobutamine echocardiography detects reversible dysfunction after thrombolytic therapy of acute myocardial infarction. Circulation 1993:88:405-15.
6 Marinho NVS, Keogh BE, Costa DC, et al. Pathophysiology of chronic left ventricular dysfunction. New insights from the measurement of absolute myocardial blood flow and glucose utilization. Circulation 1996:93:737-44

7 Arnese M, Cornel JH, Salustri A, et al. Prediction of improvement of regional left ventricular dysfunction after surgical revascularization. A comparison of low-dose dobutamine echocardiography with 201-Tl single-photon emission computed tomography. Circulation 1995;91:2748-52.

8 Qureshi US, Nagueh SF, Afridi I, et al. Dobutamine echocardiography and quantitative rest-redistribution 201-Tl tomography in myocardial hibernation. Relation of contractile reserve to 201-Tl uptake and comparative prediction of recovery of function. Circulation 1997:95:626-35.

9 Afridi I, Kleiman NS, Raizner, et al. Dobutamine echocardiography in myocardial hibernation. Optimal dose and accuracy in predicting recovery of ventricular function after coronary angioplasty. Circulation 1995:91:663-70.

10 Pasquet A, Robert A, D'Hondt AM, et al. Prognostic value of myocardial ischemia and viability in patients with chronic left ventricular ischemic dysfunction. Circulation 1999;100:141-8.

11 Gioia G, Milan E, Giubbini R, et al. Prognostic value of tomographic restredistribution thallium 201 imaging in medically treated patients with coronary artery disease and left ventricular dysfunction. I Nucl Cardiol 1996;2:150-6.

12 Cleland JGF, Freemantle N, Ball SG, et al. The heart failure revascularisation trial (HEART): rationale, design and methodology. Eur J Heart Failure 2003;5:295-303.

13 McGowan JH, Cleland JGF: Reliability of reporting left ventricular systolic function by echocardiography: a systematic review of 3 methods. Am Heart J 2003; 146:388-97.

14 Hervas I, Osca J, Perez-Pastor JL, et al. Radioimmunometric assay of natriuretic peptide type-B (BNP) in heart failure. Nucl Med Comm 2003;24:61-9.

\section{IMAGES IN CARDIOLOGY}

\section{Severe valvar aortic stenosis in a child with familial hypercholesterolaemia}

A 2 year old male child, born of second degree consanguineous marriage, presented with multiple, nodular, raised, firm, yellowish cutaneous swellings, each 1-2 cm in size, over the knees, elbows, ankles, buttocks, and the extensor aspect of wrist and hands (upper panels). The cutaneous lesions were suggestive of tuberous xanthomas. The child was evaluated and found to have severe dyslipidaemia. An echocardiogram done at that time showed the valves and chambers were normal. This patient satisfied the criteria for the diagnosis of familial hypercholesterolaemia ( $\mathrm{FH})$.

The child, who was lost to follow up, presented three and half years later with a cardiac murmur. Echocardiographic evaluation found the child having severe aortic valvar stenosis with a peak gradient of $118 \mathrm{~mm} \mathrm{Hg}$ and mild aortic regurgitation (lower panel). The aortic wall near the valve was thickened and echogenic. There was no supravalvar narrowing. He had high concentrations of total and low density lipoprotein cholesterol, while high density lipoprotein cholesterol and triglyceride values were normal. His parents were not willing for him to undergo further evaluation and management. Aortic valvar gradients in familial hypercholesterolaemia are usually caused by supravalvar narrowing. Pure valvar aortic stenosis is rare in $\mathrm{FH}$, especially in young children.

\section{S Harikrishnan \\ C K Byju \\ J Tharakan}

drhari@sctimst.ac.in
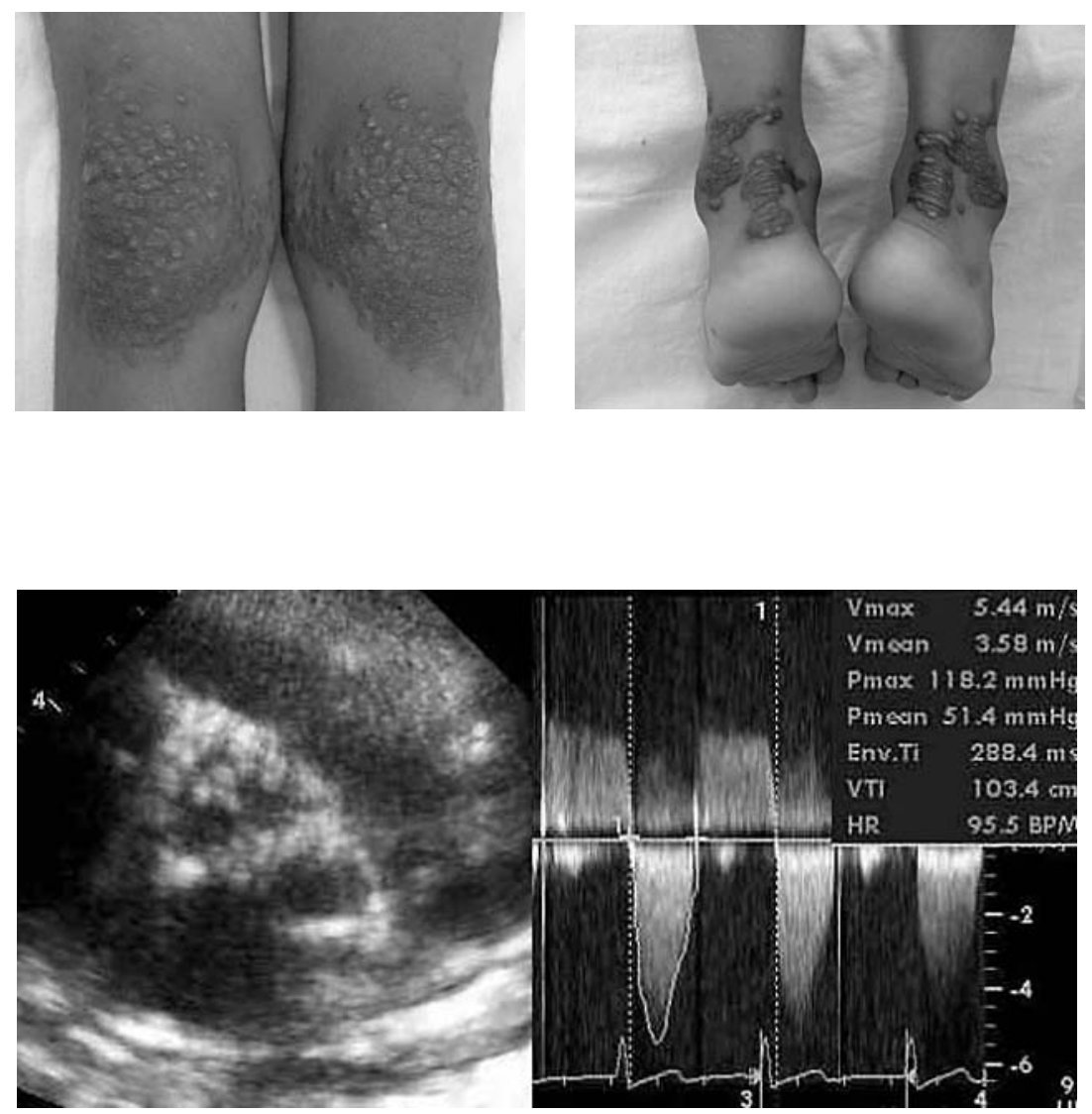